\title{
Pragmatic and Cross-Cultural Workings of Perlocutionary Intertexts
}

\author{
Jian-Shiung Shie ${ }^{1}$ \\ ${ }^{1}$ College of English and International Studies, Wenzao Ursuline University of Languages, Kaohsiung, Taiwan \\ Correspondence: Jian-Shiung Shie, c/o Department of English, Wenzao Ursuline University of Languages, 900 \\ Mintsu 1st Road, Kaohsiung 80793, Taiwan. Tel: 886-7-342-6031 ext. 5304. E-mail: jsshie@mail.wzu.edu.tw
}

$\begin{aligned} & \text { Received: June 30, } 2014 \quad \text { Accepted: August 14, } 2014 \quad \text { Online Published: October 1, } 2014 \\ & \text { doi:10.5539/ijel.v4n5p1 }\end{aligned}$
URL: http://dx.doi.org/10.5539/ijel.v4n5p1

\begin{abstract}
s
Perlocutionary intertexts (PIs) have received little attention in the literature on nonliterary discourse. This paper explores PIs in spiked article titles. A textual survey and intertextual analysis were conducted to probe into the pragmatic and intertextual workings of the PIs and their potential appeals. It is found that 1) the sociocultural knowledge for the activation of the PIs is primarily derived from formulaic language, prominent literary/non-literary works, and media products; 2) pragmatic foregrounding attracts the reader's attention; 3) the common ground derived from the source text forms the basis of the intertextual association; 4) external intertextuality triggers the pragmatic inferencing of the PI meaning and/or significance; and 5) internal paratextuality confirms or further develops the pragmatic inferencing. In addition, a post hoc questionnaire survey with 83 Taiwanese college students and their reading-response logs indicate that such intercultural PIs are moderately appealing, with their repellent effects upon the unknowing readers nullifying some of their attraction.
\end{abstract}

Keywords: perlocutionary intertexts, the source text, the alluding text, pragmatic acts, pragmatic foregrounding

\section{Introduction}

Perlocutionary intertexts promote the connections and interactions between two spans of text, with the later textual span (or 'alluding text') reflecting or referring indirectly to the prior textual span (or 'source text') in such a way that the meaning of the later text can be perceived or inferred based on the prior one. By a span of text, here is meant a word, a phrase, a sentence, or a coherent group of sentences. Thus the alluding text "Culture: it's not the economy, stupid!" (the title of a spiked magazine article published on 5 July 2011) reflects or refers indirectly to the source text "It's the economy, stupid!" (Bill Clinton's well-known campaign slogan in 1992). In a news headline or magazine article title, such intertextuality is a specific pragmatic mechanism for the reader to associate the alluding text with the source text, thereby motivating the reader to interact with a relevant piece of culture, arousing the reader's interest, and hence drawing the reader into the body copy. In this paper instances of pragmatic intertextuality in magazine article titles are referred to as "perlocutionary intertexts" (henceforth PIs).

A PI represents a situated speech act. The activation or evocation of the source text can be viewed as the realization of a perlocutionary act, which, according to Austin (1962, p.101), produces "certain consequential effects upon the feelings, thoughts, or actions of the audience". A PI has a perlocutionary act potential. It is a wordplay or a language game that can catch the reader's attention and arouse their interest better than a straightforward expression. The PI readers/hearers need to activate the knowledge about the source text and use it as a frame to infer the meaning of the alluding text. The readers who thus comprehend or appreciate the alluding text are positively disposed toward the text (cf. Irwin, 2002) and drawn further into the reading matter. When this happens, the reader's affinity with the text is generated or enhanced as a consequential effect.

This article explores the pragmatic functions and effects of PIs in the article titles of the Western magazine spiked (targeted at British readers). More specifically, the following three questions will be addressed:

1) What is it that constitutes the common ground or sociocultural background knowledge for the operations of PIs in spiked article titles?

2) How do such PIs achieve their pragmatic functions and stylistic effects?

3) To what extent can such PIs get activated by and appeal to Taiwanese readers?

For this study, a textual survey and intertextual analysis were conducted on all the 615 spiked magazine articles published during the eight months ending on 31 October 2008 (available at http://www.spiked-online.com/). The 
instances of PIs in the titles of the spiked magazine articles were identified and analyzed in light of a reader-oriented approach grounded in pragmatic acts, common ground, pragmatic inferencing, pragmatic foregrounding, intertextuality, and paratextuality. In addition, to explore the cross-cultural appeal of such PIs, a brief learning program and retrospective survey were conducted with 83 Taiwanese college students, who also wrote reading-response logs about their experience of reading such intercultural PIs. The next section presents the theoretical basis for exploring PIs. Section 3 is devoted to the textual survey. Section 4 contains the intertextual analysis. Section 5 reports on the learning program and retrospective survey. The last section is conclusion.

\section{Demarcation and Theoretical Background}

This section briefly presents the theoretical elements that form the basis for the definition, identification, and analysis of PIs in the titles of spiked magazine articles, including the concepts of pragmatic acts, common ground, pragmatic inferencing, pragmatic foregrounding, intertextuality, paratextuality, and reader-orientedness.

\subsection{Pragmatic Act, Common Ground, and Pragmatic Inferencing}

As noted earlier, a PI represents a situated speech act. The activation or operation of the intertextaul source text has perlocutionary effects. A PI in the title of a magazine article can serve to attract and persuade the reader where a straightforward expression would not. The process is like a guessing game that produces a sense of secrecy or even mystery via an appeal to the reader's curiosity. The reader has to notice or make out something unknown to them (the source text) at the time of reading. On the other hand, they are informed of the alluding text from which they can infer the answer. The reader who comprehends a PI is positively disposed toward the text (cf. Irwin, 2002).

A PI can be activated to perform what Mey (2001) terms a "pragmatic act", a pragmatic theory which deals with the verbal behaviour within the affordances of the context. The situated speech acts "rely on, and actively create, the situations in which they are realised" (Mey 2001, p. 219). The theory of pragmatic acts has been applied to quite a few recent studies on the use of language, such as Kecskes (2010) and Tseng (2010). In the situational context of the title of a magazine article, the occurrence of a PI represents a "pract" to realize the generalized pragmatic act (or "pragmeme", cf. Mey, 2001, 2010; Capone, 2005) of inviting in situational use, namely to tickle the reader's fancy and draw the reader into the body copy. A title that pitches the article's appeal expresses a pragmatic act of inviting, as is the case with the following advertising text that appeals to the reader by its semantic clash: "I brought some sushi home and cooked it; it wasn't bad," which is treated in Mey (2001,pp. 207-208) as a "pragmatic act of inviting". As I see it, in addition to PIs, rhyming words, adapted idioms, punning words, metaphors, metonymies, and the like can also be conceptualized as a device to produce individual pragmatic acts that substantiate or realize the particular pragmeme of inviting the reader to read the body copy in the situated sociocultural context of magazine or newspaper reading.

Common ground is the presupposition taken by the speaker as common or shared knowledge of people in conversation and other joint activities (Clark, 2006; Stalnaker, 2002). Common ground is a property of a community of people, even though the community may consist of only two members (Clark, 2006). Discourse participants take certain shared knowledge to be common ground, and when they make assertions during discourse, they add to their common ground. Thus common ground is dynamic. It can be added, reduced, or adjusted during discourse. Kecskes and Zhang (2009) divided common ground into core common ground (assumed shared knowledge, a priori mental representation) and emergent common ground (emergent participant resource, a post facto emergence through use). These two types of common ground converge to form a dialectical socio-cultural background for communication. Where the comprehension of a PI is concerned, the source text constitutes the core common ground (or assumed shared knowledge) in the realization of the intertextual pragmatic act. When the alluding text is recognized as a formal or semantic variant of the source text, the intertextual association is perceived, which constitutes the emergent common ground. The core and emergent common ground both contribute to the execution of the perlocutionary force in the situation.

The meaning of a PI is not encoded in language but hidden between the alluding and source texts. Such hidden meaning needs to be inferred pragmatically by the reader from the shared knowledge about the source text; the textual, situational, and sociocultural contexts of the alluding text; and the associations between the alluding and source texts. In general, the alluding text is adapted or quoted from the source text. Parallels between the two texts trigger the process of inferring the meaning and significance of the implicit intertextual association. The alluding text evokes a previous source text that embodies specific sociocultural knowledge. Identicalness or commonality in phrasing, structure, or prosody between the alluding and source texts activate the reader's awareness of and draw the reader's attention to the pragmatic intertexts in question. In due course, an emerging 
frame arises in response to the source text that the reader can draw upon to infer the meaning of the allusion. More specifically, on the basis of the intertextual association and the knowledge about the source text, the pragmatic meaning of the alluding text is inferred or its stylistic significance achieved.

\subsection{Pragmatic Foregrounding}

The foreground is that part of a discourse which presents the main point(s), while the background refers to the textual material that assists, amplifies, or comments on the speaker's goal (Hopper \& Thompson, 1980). Foregrounding involves the use of specific linguistic features to present the foreground in contrast with the background. In literary aesthetics, the term 'foregrounding' can be understood as purposeful deviation from the norm. Foregrounding prompts defamiliarization, evokes feelings, and prolongs reading time (Miall \& Kuiken, 1994). According to Mukařovský (1964), foregrounding effects (such as novelty and unusualness) result from the violation of not just linguistic rules but literary conventions as well. In nonliterary language, foregrounding functions to attract the reader's attention more closely to the subject matter (Mukařovský, 1964, p.19). Rhetorical devices (such as metaphor and allusion) can also signal the relative weigh of information (Polanyi \& Hopper, 1981). Cotrozzi (2010) makes a distinction between structural foregrounding and pragmatic foregrounding: the former refers to the relative weight of materials located on the storyline of a narrative, and the latter to the concept of deviation from a standard. From the foregoing it can be said that the title of a magazine article is a foregrounded span of text, which indicates the main idea of the article or focuses on a notable dimension of the article to catch the reader's attention. As we will see in the following intertextual analysis, PIs are a useful device employed to achieve pragmatic foregrounding, marked with a deviation from the normal frame of the source text.

\subsection{Intertextuality and Transtextuality}

Julia Kristeva (1967) launched the concept of intertextualité in semiotic theory and literary studies (cf. Juvan 2008). For Kristeva (1969, p. 443), intertextuality is "textual interaction produced within the text itself", indicating "how the text reads history and locates itself in it". The text, as she puts it (Kristeva, 1980, p. 36), is a "trans-linguistic apparatus that redistributes the order of language by relating communicative speech [ . . ] to different kinds of anterior or synchronic utterances." Thus the text is more than just an end product of language use. It also provides a historical and synchronic social context within which the activity of meaning construction is stimulated and facilitated between the interlocutors.

In its post-modern sense, the term 'intertextuality' can encompass all possible associations between a given text and other texts that may come to readers' minds (Hylen, 2005, p. 49). Granted that intertextuality is potentially inherent in all texts, some texts are more intertextual than others (Gale, 2000). As I see it, notable categories of higher degree of intertextuality include at least plagiarism, quotation, paraphrase, echo, and allusion. Viewed from the angle of semantics, plagiarism is the least original, while echo and allusion the most creative. Where pragmatics is concerned, plagiarism must involve authorial intention, but the reader may not perceive the intertextual associations. Echo and allusion may not be intended consciously by the author, but the reader has to perceive their intertextual connections. With reference to rhetoric, echo and allusion are treated as a trope. Some authors even view allusion as the metaphorical connection between two texts (as in Hollander, 1981; Pasco, 1994; Porter 2008). Due to space limitation, this article will focus only on echo and allusion, which can be defined as an indirect reference that the reader can perceive, with the alluding text quoting or reflecting the source text in such a way that the reader can perceive or infer the meaning of the former based on the latter. The alluding text of an echo or allusion is produced by adapting or directly quoting the source text.

In Babuts' (2009) view, even though allusion may have a wider dynamics and refer to another text to draw a parallel, "there is fluidity at the boundary of echo and allusion, and some elements of one may wander into the space of the other" (ibid., p. 17). Other authors (e.g., Hollander, 1981; Paulien, 2001; Perri, 1978) hold that authorial intention distinguishes the two: While the use of allusion is deliberate, the production of echo is unconscious. The problem is that a past author's intention is by and large historically unavailable to an intertext researcher. In most cases, it is not possible to verify that the author was indeed conscious of the associations between the two intertexts at the time of writing. Furthermore, based on a reader-oriented approach, the present paper focuses on the intertextual connections as evidenced in the text rather than the authorial intention. Under the assumption that it is primarily the reader who makes meaning, this paper emphasizes the reader's participation in activating an echo or allusion. Therefore, echo and allusion are treated in this paper as one single type of pragmatic phenomenon without drawing a line between the two, as do Brunson (2003), Mathewson (2003), and Lennon (2004). For both allusion and echo in their situated use, the phrase 'perlocutionary intertexts' (PIs) is used as a cover term in the present paper. 
Genette (1997) provides a model to account for the manifold relationships that a text may have with other prior texts. He theorizes "transtextuality" (rather than intertextuality) as the general concept of various relationships between two or more texts and recognizes five modes of transtextual relationships, of which two are particularly relevant to the present study: intertextuality and paratextuality. The former is defined as the "presence of one text within another" (ibid., p. 2), as in quotations and allusions. The PIs explored in the present paper also involve what Genette calls "intertextuality." Furthermore, paratextuality is a transtextual mode that associates a text with its paratexts, that which surrounds the main body of the text, such as title, subtitle, notes, and illustrations (ibid., p. 3). We will see that PIs in the titles of spiked articles interact with the relevant parts of the body copy, or its paratexts.

\subsection{The Reader-Oriented Approach}

As noted earlier, the present study takes a reader-oriented approach to pragmatic intertextuality. In this approach, "the alluding author is ultimately a figure (re)constructed from the text by the reader" (Gale, 2000, p. 6). In virtue of their consequential effects upon the reader, PIs are treated in this study as the intertextual associations perceived or constructed by the reader. In Barthes' terms, a text is "a multidimensional space in which a variety of writings [...] blend and clash", but the place where this textual multiplicity is focused is the reader rather than the writer (Barthes, 1977, p. 148). The linkage and interaction between an alluding text and its source text occur in the mind of the reader. Thus anything perceived by a reasonably proficient reader as meaningful intertexts should count as such. Although the same text may evoke more than one legitimate interpretation for readers with different background knowledge, "a fair degree of consensus can be reached amongst a readership which shares a common culture - that is, a readership familiar with the same range of potential intertexts and strategies of reading and interpretation" (Gale, 2000, p. 4).

An alluding text entails a source text, but a source may not cause a PI since that source may not be evoked (cf. also Ricks, 2002, p. 3). Whether a source text can come into play depends on the reader's familiarity with that source text, which is grounded in the culture of the speech community. An alluding text does not release "a single 'theological' meaning (the 'message' of the Author-God)" (Barthes, 1977, p. 148). It is the reader who anchors the meaning of a PI. Barthes (1981, pp. 43-44) divides readers into two categories: "consumers" (who read for stable meaning) and "readers" (who construct or produce meaning). The constructive readers are able to recognize, comprehend, and appreciate PIs. In a similar vein, Pucci (1998) theorizes "the full-knowing reader" as being able to grasp the meaning of an allusive text. A full-knowing reader, according to Pucci (1998), does not need to have a complete knowledge of all that the allusion can mean. It is the assumption of the reader's "complete interpretive power over the allusive moment" that makes the allusion reader full-knowing (Pucci, 1998, p. 43). Such a reader is historically sensitive to the intertextual connection and interested and active in the meaning construction and interpretation, who, assuming complete interpretive power over the allusive moment, adds something to the alluding text that is otherwise not there in line with the intertextual linkage. The identification of PIs for this study relies on such constructive readers, to which we will return in the following section.

\section{The Textual Survey}

A textual survey was conducted to identify PIs in spiked article titles in accordance with the definition of a PI given in the beginning of the present paper. Launched in 2001, spiked is Britain's first online-only current-affairs magazine, which gives incisive critical comments on current affairs, often from the viewpoints of humanists and libertarians, emphasizing free speech, moral autonomy, and Enlightened spirit (cf. O'Neill, 2011). The magazine describes itself as "a metaphorical missile against misanthropy." (Note 1) Granted that this magazine is not targeted toward Eastern readers, it was chosen as the source of PI data for the present study primarily because of its eye-catching article titles abounding in PIs grounded in Western cultural sources. A textual survey and intertextual analysis of PIs were conducted on all the 615 spiked magazine articles published during the 8 months ending on 31 October 2008.

The textual survey was done by the following 4 knowing readers: a Taiwanese professor of linguistics, a Taiwanese lecturer of English, a Taiwanese associate professor of literature, and a native-English-speaking Catholic sister. Each of the 4 readers independently identified instances of PIs in the 615 spiked article titles. To take paratextuality into account, they also surveyed the body copies of the spiked articles. The textual survey was done first by the present author, subsequently by the other three readers, who focused particularly on the titles and parts of a title that had not been marked by the present author as containing a PI. A self-administered retrospective email survey conducted after the textual survey indicated that the four readers were all interested and active in identifying PIs during the textual survey. In addition, their notes taken during the textual survey 
showed that they were able to associate the identified alluding text with the source text. Thus they were historically sensitive to the source text where the identified instances of PI are concerned.

The four readers identified instances of PIs according to the characterization of PIs in the beginning of this paper. The title of a spiked article was marked as containing an allusion or echo in light of the following conditions. First, a span of text in the title (namely a word, a phrase, a clause, or the whole title) reminded the reader of an earlier textual span (the source text) due to the formal or conceptual similarity of the former to the latter. Second, the reader could perceive or infer the meaning of the alluding text in the title based on the source text. Third, the reading or inferred meaning made sense and cohered with the context of the magazine article. As a result, the four Taiwanese academics jointly activated and identified 172 PIs from the spiked article titles, accounting for $28 \%$ of all the 615 spiked article titles.

More than one PI in every four titles (28\%) was identified. Thus it can be said that PIs frequently arises in spiked article titles, much more frequently than the allusions and echoes identified from the news headlines of the national edition of The New York Times published within the same time frame (namely the eight months ending on 31 October 2008). According to Shie (2011a), only 69 allusions or echoes were found in the sampled 605 New York Times news headlines (11.4\%). Allusions and echoes occurred even less frequently (1.8\%) in the news headlines of the Times Supplement published for international readers during the same period of time (Shie, 2011a) (Note 2). The frequency variations can be attributed to the factor of cultural proximity or target audience. In general, people gravitate toward media products that are closer to their own culture in cultural content and style (cf. Straubhaar, 2007, p. 26). The activations of allusions and echoes rely on the common ground or shared knowledge of the source text, which is usually characterized by its close cultural proximity to the target audience. Times Supplement articles (targeted toward international non-native English speakers) are culturally farther from the general reader than spiked articles (targeted toward British people). Thus it is understandable that PIs occur more frequently in spiked article titles than in Times Supplement headlines. The higher degree of internationalization of The New York Times has made itself less culture-specific or more culturally neutral than spiked. Thus the globalized newspaper is culturally farther from the general targeted readers than spiked as well. As a result, fewer PIs can be found in the New York Times headlines than in spiked articles titles.

\section{The Intertextual Analysis}

An intertextual analysis of the 172 full-length spiked articles containing the PIs was undertaken by the present author to explore 1) the common ground (or sociocultural background knowledge) for the operations of the PIs and 2) the ways in which the PIs achieve their pragmatic functions and stylistic effects. As the intertextual analysis reveals, the source texts of the 172 PIs fall into 6 basic categories. Table 1 lists and exemplifies the 6 categories in descending order of occurrence frequency. The last category 'other wordplay' covers all instances of PIs that do not belong to the other 5 categories.

Table 1. Categories of PIs in terms of source texts

\begin{tabular}{lll}
\hline $\begin{array}{l}\text { Categories } \\
\text { - Subcategories }\end{array}$ & $\begin{array}{l}\text { Ocu } \\
\text { times }\end{array}$ & Example of a PI source text \\
\hline Formulaic expressions: & 62 & \\
- Idioms & 21 & An iron fist in a velvet glove \\
- Proverbs, sayings & 16 & Man's home is his castle. \\
- Slogans, catchphrases & 9 & Because you're worth it. \\
- Neological compounds & 7 & Watergate \\
- Context-specific formulas & 9 & And the (prize) goes to (a winner). \\
\hline Literary / non-literary works & 40 & \\
- Literary works & 18 & The lady doth protest too much. \\
- Bible & 8 & And a little child shall lead them. \\
- Non-literary works/theories & 14 & Small is beautiful. \\
\hline Media PIs & 36 & \\
- movies & 12 & Back to the future \\
- TV shows / soap operas & 10 & Hollyoaks \\
- Pop songs / albums & 14 & I Predict a Riot. \\
\hline Historical events & 13 & The phoney war \\
\hline Folktales \& children's songs & 9 & Who's Afraid of the Big Bad Wolf? \\
\hline Other wordplay & 12 & (Parents') liberation movement \\
\hline
\end{tabular}


The categories of source texts given in the table jointly present a general picture of the common ground or sociocultural background knowledge for the operations of PIs in spiked article titles. In the remainder of this section, we consider cases of PIs in each of the 6 categories and discuss their intertextual operations, pragmatic functions, and stylistic effects in context. To provide necessary situational information, each discussion of a PI below needs to begin with a brief introduction to the body copy of the magazine article.

As shown in Table 1, formulaic expressions (such as idioms, proverbs, sayings, slogans, catchphrases, and context-specific formulas) account for the largest category of PIs in the spiked article titles (62 out of 172, or 36 $\%)$. Part of the attraction of a formulaic intertext can be ascribed to the sociocultural significance of its source text, whose salience is conducive to the attention-catching quality that helps realize the pragmeme of invitation. Idioms, proverbs, sayings, slogans, and catchphrases are culturally shaped and deeply embedded in the socio-cultural norms of a particular speech community (cf. Prodromou, 2008, p. 28). They are closely associated with sociocultural contexts (Kecskes, 2000; Van Lancker Sidtis, 2004). Solidarity or identification with a sociocultural group is signaled by a range of formulaic expressions, especially idioms. Furthermore, formulaic expressions frequently entail an evaluative stance. As Van LanckerSidtis and Rallon (2004, p. 208) put it, "formulaic expressions are generally laced with attitudinal or emotional innuendoes". They often carry emotional or attitudinal content as part of the wordplay and humor that facilitate the pragmeme of invitation. To illustrate, the following title contains a PI that is based on an idiom:

(1) An iron fist in a velvet glove. (12 May 2008, spiked)

The spiked article is a review of the superhero film Iron Man, which captures the "contradictions in humanitarian militarism", as noted in the article. In the film, arms manufacturer Tony Stark is taken captive by terrorists and forced to build an armored suit. The powered armor ultimately helps him escape captivity. As Iron Man, he subsequently locates the terrorists' headquarter and blows up their stockpile of mass destruction. In the battle, Iron Man kills the bad guys and saves the civilians used as human shields. He manages to prevent a massacre and skillfully minimize the damage.

The whole title in (1) is a PI with identical alluding and source texts. The source text is the metaphorical idiom an iron fist in a velvet glove, describing a person who seems to be gentle but is in fact severe and firm. But in the context of the spiked article, the idiom depicts Iron Man's strength and determination with subtle gentleness or caution. The meaning construction is achieved through pragmatic inferencing in the context. The noun phrase an iron fist is taken metaphorically in the idiomatic source text. But when it comes to the alluding text, it can be taken literally, referring to Iron Man's attacking fist, and/or metaphorically, connoting Iron Man's superhuman strength and unyielding attitude. In both the alluding and source texts, a velvet glove evokes the concept of gentleness or caution. Even a knowing reader cannot know that the article is about the superhero film at the first glance of the title in (1). By that time the reader does not have enough information from which to derive the meaning of the alluding text. But the foregrounded idiom in the title can arouse the curiosity of the knowing reader (who is aware of the idiom in question) and induce him to read the body copy. Only when the reader reaches the body of the article can he acquire sufficient information to do the reasoning, say, from an iron fist in the idiom to Iron Man's attacking fist. This means that, in addition to drawing upon his knowledge about the idiomatic source text, the reader has yet to rely on the paratextual (Genette, 1997) associations and references between the title and the body copy. To be brief, the PI in the title draws the reader into the article, and then the paratextual associations, in conjunction with the PI, directs the reader toward the main points of the article.

Idioms are conventionalized multiword expressions with limits on their size (Fernando, 1996). The lower limit for the size of an idiom is established by the compound. An idiomatized compound occurs as a multiword expression representing habitual co-occurrences between two or more words (Fernando, 1996). Seven PIs with a source text in the form of a neological compound were identified in the textual survey. For example:

(2) 'Brandgate': turning crudity into a crisis. (30 October 2008, spiked)

The article is concerned with the obscene voice messages that English entertainers Russell Brand left as prank telephone calls in the BBC show The Russell Brand Show. Because of the incident, Russell Brand resigned afterwards from the BBC. Invented for the particular pragmatic situation, the nonce compound Brandgate in (2) conforms to the internal structure of the compound Watergate: The element -gate is preceded by the name of the main character the article features to denote a scandal or wrongdoing. The shared structural feature of the alluding text (Brandgate) and source text (Watergate) enabled the reader to activate the source text and grasp the meaning of the alluding text. Two types of textual correspondences are at work for the reader to construct the intertextaul meaning: 1) the internal paratextuality between Brandgate and the spans of texts about the Russell Brand incident in the body copy and 2) the external intertextuality between Brandgate and Watergate, with 
President R. M. Nixon mapped onto Russell Brand, the burglary of the Watergate building onto Russell Brand's obscene voice messages, and the President's resignation to Russell Brand's resignation.

Nine PIs with a context-specific formula as its source text were identified in the textual survey. The following is an example:

(3) And the gold for cynicism goes to. . (28 August 2008, spiked)

The title in (3) reminds the reader of the formulaic expression And the (prize) goes to (a winner), which recurs in a specific context, namely a winner announcement. Such a prototypical formulaic construction cannot be traced easily to a canonical source owing to recurring renditions of its basic frame, which may be called a 'context-specific formula'. The PI in (3) satirizes the public cynicisms in Britain after the 2008 Olympics, such as the criticism about the underachievement of the English football team and the complaint that the government was not investing enough in sports development. The situational context of the alluding text in (3) encompasses the British team's failure to meet the medal expectations in the 2008 Olympics. The source text or the winner announcement - And the (prize) goes to (a winner) - is the common ground required to activate the intertextuality in question. The alluding text - And the gold for cynicism goes to... - deviates from the discursive norm of a medal presentation which the source text represents. The term or concept cynicism is the foreign element that intrudes into the frame of the prototypical medal presentation. This deviation is what produces the effect of pragmatic foregrounding to catch the reader's attention.

The second largest category of PIs is those involving a literary work or a work or theory in the field of a non-literary discipline. A total of 40 PIs (40 out of 172, or $23.3 \%$ ) were identified which are grounded in knowledge about a prominent literary work or nonliterary publication, accounting for a significant part of the sociocultural background knowledge necessary for activating the PIs. If such knowledge is common or familiar enough to the reader, it will form an intertextual common ground that catches the reader's attention and aids the realization of the pragmatic act of inviting the reader to read the body copy. Twenty-six article titles in the data allude to a literary source (including the Bible), as in:

(4) The student doth protest too much. (4 March 2008, spiked)

The article comments on the protest of nine teenage girls at a north London Jewish comprehensive school, who refused to take a test on Shakespeare because of his alleged anti-Semitism, as expressed in his negative portrayal of Shylock (the Jewish moneylender) in The Merchant of Venice. The title in (4) is a tacit reference to the following line in Shakespeare's Hamlet: "The lady doth protest too much" (Hamlet, Act 3, Sc. 2), uttered by Queen Gertrude while she is watching a play that simulates her ex-husband's (or Hamlet's father's) death. In that line 'the lady' refers to the Player Queen (the queen in the play that Queen Gertrude is watching). The play inside the play is designed by Hamlet to test King Claudius' (or Hamlet's uncle's) guilt of murdering the late King Hamlet. The source text "The lady doth protest too much" remarks upon the Player Queen's solemn declaration that she will never consider remarrying, suggesting that Queen Gertrude, who has been in a situation similar to the Player Queen's, is indirectly defending her own remarriage. A rough memory of this part of the storyline will suffice to activate the intertextual overtones of the PI in (4) and bring forth its emotional effect.

The formal, structural, and conceptual similarities between the alluding and source texts (with only one word different) allow a knowing reader to discern the presence of the PI in (4). Through the intertextual association, the title in (4) gives unusual prominence to the author's argument against the students' refusal to take the test on Shakespeare - namely, that the students protest so much as to lose their credibility. In particular, the foregrounding effect is further strengthened through the use of the archaic word doth, which is set off from the contemporary language of the text. Thus the title can catch the reader's attention, temporarily shifting the reader's attention away from what is expressed to how it is expressed. Not knowing about the source text, an unaware reader may still comprehend the plain, literal title in (4). But in this case the unaware reader will not be able to enjoy or appreciate the infotainment with the Shakespearean intertexts, where the foregrounded PI draws attention to the linguistic form of the alluding text and then triggers the pragmatic inferencing between the alluding and source texts. The Player Queen's solemn vow, a piece of knowledge the knowing reader already has, constitutes a premise from which the conclusion about the students' protest can be inferred. Such a PI contributes to conveying the message in an entertaining way. The act of expression is placed in the foreground, through which the semantic or conceptual content is highlighted as well. Thus, in this instance the poetic function (appreciation or entertainment) of the PI enhances its cognitive function (perception or comprehension).

In addition, 14 PIs in the data are found to have a source text deriving from a non-literary work or theory. For example: 
(5) Small is not beautiful. (23 April 2008, spiked)

This spiked article critiques the argument that small-scale, organic production in the developing world can solve global food problems. The title in (5) activates in the knowing reader's mind knowledge about Small Is Beautiful, a classic economics book by E. F. Schumacher (1975), in which many modern concepts of ecological economics are based. The author opposes the bigger-is-better philosophy of mainstream economics. As Schumacher puts it (1975, p.34), "Ever bigger machines, entailing ever bigger concentrations of economic power and exerting ever greater violence against the environment, do not represent progress: they are a denial of wisdom."

A knowledge frame can be evoked by its own negation (Lakoff, 2004). The negative statement in (5) evokes a frame of knowledge about the concept 'small is beautiful' as common sense in economics. The negation of the statement represents a reframing of the concept. The knowing reader's awareness of the implicit intertextuality is activated by the similarities in phrasing and structure between the source text and its negation as the alluding text. Residing between the source statement (namely Small is beautiful) and its negation, the meaning of the PI in (5) can be inferred from the shared knowledge about the evoked source frame and its reframing. The emerging new frame breaks down the ways the issues have been framed by showing - via the paratextual links between the title and body copy - that the facts and conditions do not fit the evoked frame (small-scale, organic production cannot solve the global food problems) and that new facts and conditions can fit the new frame (e.g., the expansion of agricultural productivity has been most dramatic in the developed world).

Also frequent in the spiked titles are media PIs (36 out of 172, or $21 \%$ ), which reflect or indirectly refer to a movie, pop song, TV program, or product of other popular media, all of which are pop culture products. Pop culture products or practices are usually marketed to the masses and designed to be accessible to the widest possible audience. Thus it is usually the case that PIs involving pop culture are salient to the reader in the cultural community. Their appeal and accessibility facilitate the performance of the pragmatic act of inviting the reader to read the body copy. Such a media PI is exemplified by Hollyoaks in the following title:

(6) 'Mein Kampf for the Hollyoaks generation'. (25 July 2008, spiked)

This article is a review of the autobiography of Mark E Smith (MES), leader of Manchester band The Fall, who is "not afraid to offend people in order to attack modern taboos and liberal hypocrisy", as the reviewer describes. The title in (6) compares MES's autobiography to Adolf Hitler's infamous memoir Mein Kampf (with which MES does not agree however), suggesting that MES's autobiography is very popular but highly controversial. In the title, Hollyoaks (a long-running British TV soap opera, with the characters normally in their late teens or early twenties) alludes to the British couch-potato generation.

The title in (6) foregrounds little about the main idea of the article. The reader cannot predict the main idea of the article by reading the title alone. The media PI in (6) calls attention to itself, namely a program about young people in Britain. The source text Hollyoaks serves as a means of inducing the reader to read the body copy so that they can arrive at the gist of the article. In a sense, the common ground or shared knowledge about Hollyoaks and Mein Kampf divides the readers (including those outside the cultural community) into two groups: the knowing and unknowing readers, the latter include those who give up reading due to the inaccessibility of the title. Possessing the common ground, the knowing readers can be conceptualized as belonging to a specific emerging or ad hoc speech community. When they succeed in constructing the intertextual meaning (one that makes sense, coheres with the context, and sheds light on the reading), they become a member of the knowing community. As their identity changes from an unknowing to a knowing reader, their psychological distance from the text is shortened significantly. In general, PIs allow a knowing reader to exercise specialized knowledge. When the reader is a foreign one, the shared knowledge necessary for constructing intertextual meaning becomes a specific item of cross-cultural knowledge. Such cross-cultural knowledge about Hollyoaks is usually foreign to a non-native English speaker. The knowing readers who possess the cross-cultural knowledge may even retrieve it with significant effort or additional reading strategies, such as re-examining the context and consulting a reference work.

Another example of a media PI is given in (7), with the title of an American movie as its source text:

(7) Modern Guilt: Beck to the future. (5 September 2008, spiked)

Modern Guilt is an album that shows a more mature Beck Hansen (an American singer-songwriter), who sings about climate change and refugees. The article reviews the album positively. The phrase "Beck to the future" is a punning media PI, alluding to Back to the Future, a 1985 American science-fiction adventure film. Beck's 1994 debut album Mellow Gold was a mainstream success. He proved himself to be a true original. In the 1990s, he became one of the most outstanding alternative rock musicians. But later on he seemed to have run out of ideas. 
Around the time the article was published, Beck was reaching 40. His new album Modern Guilt, according to the reviewer, was an innovative return to form. Thus the talented songwriter was still as brilliant as he was in the 1990s.

Beck Hansen is better known as simply 'Beck'. By virtue of its punning feature in the context, the name Beck is set off from the linguistic frame of the film title Back to the Future. In fact, the word Beck in (7) is an instance of divergent spelling (or deliberate misspelling) as a foregrounding device. Intertextual foregrounding arises from the intrusion of a foreign or deviating element (such as Beck in (7)) into the knowledge frame of the source text, the omission of an existing element from the frame, or both. The knowing reader's attention is drawn to the foreign (foregrounded) element Beck in the frame of the film title. The alluding text 'Beck to the future' in (7) is a play on the lexico-syntactic frame of the well-known film title. The film title as the source text is modified by lexical substitution on a slot-and-filler basis. Where a punning PI frame is concerned, slots are positions in the construction frame, while fillers are a lexical unit used to fill a slot in light of its correlation with a homophonous or phonologically similar unit in the original frame. Through such modification of and interaction with the well-known source text, the alluding text (as well as the disrupted source text) becomes conspicuous to and invites interpretation by a knowing reader. It was found that, although one of the four readers doing the textual survey had never seen the movie, he could still activate the punning PI in question with the knowledge of merely the film title. The foreign element Beck caught his eye, evoked the source text, and led him to extrapolate the significance of the alluding text in context. Thus the PI produced perlocutionary effects upon the feelings, thoughts, and actions of the reader.

In the data for this study 13 spiked titles (13 out of 172, or $7.6 \%$ ) were found to be based on a historical event, an event taking place in history and "constituted by the actions and reactions of human beings" (Ritter, 1986, 142). The following is such a PI:

(8) The phoney war over Harry of Afghanistan. (3 March 2008, spiked)

The phrase phoney war as a source text refers to the comparative inaction at the beginning of the Second World War between the German invasion of Poland and that of Norway (Oxford English Dictionary Online). The alluding text the phoney war in (8) denotes a war of words over Prince Harry's role on the frontline in Afghanistan against the background of the real war in Afghanistan being fought by British and American forces. As the subhead goes, " $[\mathrm{w}]$ hile both bombastic defenders and shrill critics of the pact of silence are firing blanks, nobody wants to debate Britain's real Afghan war." The knowing reader may be hooked by the PI (phoney war) in the title. Illuminating the two confronting but inactive sides, the subhead (a paratext) elaborates on the PI and reels in the knowing reader. The opening paragraph of the body copy (another paratext) makes it clear further that the deal (or pact of silence) is between the British media and the Ministry of Defence to keep secret Prince Harry's role on the frontline in Afghanistan. This is how the knowing reader activates the PI in question through intertextuality and paratextuality. The reader evokes the knowledge of phoney war as a source text and notices the confrontation involving inaction during the phoney war, in light of which interpretations are made that cohere with the paratextual links between the title, subhead, and body copy.

As shown in Table 1, nine spiked titles (9 out of 172, or $5.2 \%$ ) contain a PI with a source text deriving from a folktale or children's song. Consider the following example:

(9) Who's afraid of xenotransplantation? (3 October 2008, spiked)

This spiked article argues for the research of using pig organs in human to save people who need a new organ since the supply of transplantable organs would never meet the demand. The author laments that Britain should have driven away xenotransplantation research. The title is (9) is based on the intertextual frame 'Who is afraid of __ ', where the slot is filled with the term xenotransplantation. The frame is derived from 'Who's Afraid of the Big Bad Wolf', an instantly popular song originally featured in the 1933 Disney animated musical short Three Little Pigs, which became "nearly universal in its spread" (Watts, 1997, p.77). In fact, the song was the first hit song to come from a cartoon (Barrier, 2007, p.97). Thus it is a piece of shared knowledge among many members of the English-speaking community. Within the popular colloquial frame, the technical term xenotransplantation is foregrounded, highlighting the theme of the article effectively. The threatening force of the marauding wolf is mapped metaphorically onto the risk of using pig organs in human (such as viral and bacterial dangers, as can be seen in the body copy). The metaphorical meaning can be constructed when the reader reaches the body of the article.

While reading the title in (9), one of the four readers doing the textual survey invoked the knowledge frame of the well-known 1962 Broadway play Who's Afraid of Virginia Woolf rather than the song 'Who's Afraid of the Big Bad Wolf'. However, the title of the play alludes to the title of the song. Through the intertextual association, 
the following underlying meaning is signified in the play: 'Who's afraid of living life without false illusions' or 'Who's afraid to face reality' (cf. Albee \&Kolin, 1988, p.52). In the data for the present study (the 615 spiked article titles), three titles were found to be based on the PI frame of this popular Disney song in question. The synchronic and diachronic proliferations of such intertexts form an intertextual sequence that can be traced back to the same canonical source. Granted that the canonical source is the most prominent source text in the whole sequence of intertexts, it is also possible that an intermediate intertext is invoked and serves as the source text or common ground of the PI.

The last category of PIs in the data covers the 12 instances of PIs that do not belong to the other five categories (12 out of 172, or $7 \%$; see Table 1). The following is an example:

(10) Why we need a parents' liberation movement. (27 June 2008, spiked)

As stated in the spiked article, instead of a women's liberation movement, what people need in the 21st century is "a parents' liberation movement, to take a stand against the infantilisation and repression of mothers and fathers that seeks to undermine both [their] family lives and ... sense of self." The phrase parents'liberation movement in (10) is an instance of intertextual wordplay (or linguistic entertainment), which exploits the well-known source text women's liberation movement. Apparently the word women in the well-known source text is replaced by the key word parents, which is the focus of the spiked article. The common structural feature of the alluding and source texts brings about what Delabastita (1996, p.128) calls a "communicatively significant confrontation" of the two intertextual structures with similar forms and partially mapped meanings or concepts (both movements are concerned with liberation from limitation and repression). The intertextual confrontation grasps the reader's attention. In addition, the activation of the source text and the intertextual/paratextual association add to the thematic coherence of the text since the spiked article starts with a discussion of feminism and then deals with parents' liberation movement.

Through the above examples we have demonstrated how a PI achieves its pragmatic functions and stylistic effects. We have illustrated and analyzed the following elements that jointly contribute to the pragmatic functions and stylistic effects of a PI: 1) pragmatic foregrounding, namely formal or conceptual deviation from the frame of the source text, that attracts the reader's attention; 2) common ground, namely shared sociocultural knowledge about the source text, that forms the basis of the intertextual association; 3) external intertextuality between the alluding and source texts that triggers the pragmatic inferencing of the PI meaning and/or significance; and 4) internal paratextuality between the alluding text and its paratexts that confirms or further develops the pragmatic inferencing. Also noticeable is the reliance of the activation of a PI upon the common ground of the source text. Without the sociocultural knowledge about the source text, the reader will not be able to comprehend or appreciate the PI. Thus a PI can divide its readers into two groups: the knowing readers (who know the source text) and unknowing readers (who do not know the source text).

Some magazine articles have a straight title, which presents or relates to the main points of the body copy (as in (10)), while others contain a feature title, which grabs the reader's attention without directly giving the main idea of the article (as in (1)-(9)) (Note 3). A great majority of the 172 PI-containing titles in the data for this study belong to the latter type. The PIs in the feature titles draw the knowing reader into the body copy by sparking their curiosity. They realize the pragmatic act of inviting and achieve perlocutionary effects upon the feelings, thoughts, or actions of the knowing reader. It can be said that such PIs are pieces of infotainment where, in Thussu's (2007, p.8) words, "style triumphs over substance". The readers of a PI are invited to play a language game of intellectual stimulation, in the process of which relevant knowledge of the source text is evoked, contextual information is processed, the intertextual association is established, the PI meaning is inferred, and the answer is finally arrived at.

\section{The Retrospective Survey}

The comprehension or appreciation of a PI depends on the knowledge of the source text, whose textual and sociocultural meanings constitute the common ground necessary for processing the alluding text. But the knowledge or experience involved in such discursive intertextuality is not readily available to every member of the reading audience' speech community (Irwin, 2001, 2002). On the one hand, familiarity is a cause of comprehensibility and interestingness (Alptekin, 2006; Teigen, 1985; Sadoski et al., 1993). What is unfamiliar to the reader is unlikely to spark their interest. On the other, alien knowledge or culture can possibly arouse the recipient's curiosity, motivate the recipient to acquire the alien culture or experience it vicariously (namely through imagined participation in the experience of others), and, accordingly, draw the reader into the body copy (Shie, 2012). It is therefore significant to consider PIs from foreign readers' perspectives.

To explore the cross-cultural appeal of the PIs to nonnative readers of English, a brief learning program and 
retrospective survey were conducted with 83 Taiwanese senior college students of the following two intact English-major classes taught by the present author in the 2013 spring semester: 1) Cross-Cultural Communication and 2) Language and Culture. Before the retrospective survey, the 83 students were taught 8 spiked articles as supplementary course materials primarily through traditional lectures over 2 consecutive weeks ( 2 hours per week). The titles of the 8 spiked articles are given below (with the source text underlined in brackets where necessary):

(11). The student doth protest too much (4 March 2008, spiked)

(12). Fascism: it ain't what it used to be (25 April 2008, spiked)

['Fings ain't wot they used t'be', a catchphrase expressing nostalgia]

(13). An iron fist in a velvet glove (12 May 2008, spiked)

(14). And a little child shall lead them (26 June 2008, spiked)

['And a little child shall lead them' (The Bible, English Standard Version, Isaiah 11: 6), alluding to a survey revealing that children know more than their parents about healthy eating]

(15). 'Mein Kampf for the Hollyoaks generation' (25 July 2008, spiked)

(16). And the gold for cynicism goes to ... (28 August 2008, spiked)

(17). Modern Guilt: Beck to the future (5 September 2008, spiked)

(18). Who's afraid of xenotransplantation? (3 October 2008, spiked)

These titles / articles were selected according to two principles. First, one of every spiked article published in one month should be chosen whose title contains a PI. Second, the selected titles that contain a PI should cover as many categories of source texts as possible (e.g., literary works, biblical texts, idioms, pop culture products, and so on).

It was found during the pre-reading discussions that a great majority of the students were unknowing readers of the PIs in (11)-(18). In other words, most of them did not know the intertextual source texts yet. To understand the alluding texts, they had to acquire the knowledge of relevant source texts and learn to make meaningful intertextual associations, which were what the learning program was intended to achieve.

Six weeks after the intertext lessons finished, the students reviewed the articles, filled out a brief anonymous questionnaire, and wrote reading-response logs about their interest in the 8 PIs. The post hoc questionnaire asked the students to rate their interest in reading the intertexts in (11)-(18) on a five-point scale ranging from 1 to 5 , where 1 represents 'extremely uninteresting' and 5 'extremely interesting'. The results are summarized in Table 2:

Table 2. The students' responses to the survey questions

\begin{tabular}{cccccccccc}
\hline PIs & $(11)$ & $(12)$ & $(13)$ & $(14)$ & $(15)$ & $(16)$ & $(17)$ & $(18)$ & Total \\
\hline Mean & 3.42 & 2.77 & 4.31 & 4.01 & 3.28 & 4.06 & 4.09 & 4.38 & 3.79 \\
SD & 0.85 & 1.00 & 0.75 & 0.93 & 1.10 & 1.02 & 0.92 & 0.93 & 1.08 \\
\hline
\end{tabular}

$\mathrm{n}=81$ (Two of the 83 students did not participate)

In general, the students were moderately interested in reading the PIs $(M=3.79)$. It is notable that there is considerable variation among different degrees of interest in individual PIs. The students were more interested in (13), (16), (17), and (18), all of which involve pop culture products. As noted earlier, pop culture products or practices are usually marketed to the masses and designed to be accessible to the widest possible audience. Thus it is generally the case that pop culture intertexts are more appealing or accessible to foreign readers. On the other hand, the students were less interested in (11), (12), and (15). The major reason is that these intertexts or their source texts contain strange-looking or hard-to-pronounce words (such as doth, ain't, fings, Mein Kampf, and Hollyoaks), as revealed in their reading-response logs.

The students wrote their logs in English or Mandarin Chinese (the de facto official language in Taiwan). They were prompted to write about two most interesting and two most uninteresting titles, identify the source texts, and briefly give the reasons why their selected intertexts were interesting or uninteresting. Eighty students submitted their logs. The $80 \operatorname{logs}$ contain a total of 60,739 words (measured by the word count in Microsoft Word). 
It can be seen from the logs that as many as 51 students thought of (15) as one of the two most uninteresting titles. For them the intertext in (15) was inert. They did not know the German expression Mein Kampf, had never read the memoir, had no idea about any episode of the soap opera Hollyoaks, and hence failed to grasp the connection between Mein Kampf and Hollyoaks, as one student wrote:

'Mein Kampf for the Hollyoaks generation' is associated with an English soap opera starring a group of English young people. But I only know some British movie stars. Such TV actors are very unfamiliar to me. I think this is probably because of cultural differences. Thus I couldn't trace the source of this intertextual title. It looked strange and unimpressive. Besides, the [6-word] title contains three words unknown to me. So I didn't want to make sense of it. Neither did I want to keep reading the article (Note 4).

The intertext in (12) was taken by 43 students as one of the two most uninteresting. Apart from their dislike or even aversion toward fascism, they most frequently expressed their lack of knowledge about the source text and failure to make sense of the colloquial or nonstandard word ain't. The following is an excerpt from the logs:

I think "Fascism: it ain't what it used to be" [ . . ] is very uninteresting to me [ . . ]. The reason [ . .] is that, first, I am not familiar with those original texts. When I am not familiar with the first text, I can't really have any connection with the second text either. [...] The connections and interactions between text 1 and text 2 of "Fascism..." are just not so well-connected and maybe even a little bit of plain. Text 1 is simply cut down and pasted onto text 2, giving them a little bit of different concept, [. . .]. "Fascism: it ain't what it used to be," is simply added with an old proverb behind the subject "Fascism." No further creativity is the reason why I think the intertext [ . . . ] failed to get me engaged.

It is also notable that 33 students regarded (11) as one of the two most uninteresting titles. Many of them were not interested in literature. They knew very little about Shakespeare's works or felt them tedious. This is understandable since most of them studied English primarily for practical purposes, with English Literature offered to them merely as an elective course. Such a mindset is reflected, for instance, in the following excerpt:

'The student doth protest too much' is derived from Shakespeare's Hamlet. I was not interested in it [the intertext] because I was not interested in English literature at all. Worse yet, when I saw the word doth in the title, my interest to read the article was further diminished. In addition, I could not perceive the intertextual link. I felt that it was just a play on old English words intended to show off eruditeness. It was a sentence that made me feel troublesome. Later on, when I was taught the intertextual link and understood the reason why the author used the word doth, I remained reluctant to read the article. For I felt that the article would be mind-numbing, full of features of English literature (Note 5).

On the other hand, the students gave specific reasons why their selected titles could catch their attentions and make them feel like reading the body copies. They described as interesting the song, the movie or an awards ceremony associated with the PI in (16), (17), or (18), which contributed to the engagingness of the intertextual title. One student mentioned that she had watched Back to the Future several times with her father since the film was his favorite. Thus she rated (17) as extremely interesting. The idiom in (13) was also eye-catching in that it reminded many students of one of their favorite film series Iron Man. At the time of the survey, Iron Man 3 happened to be released in Taiwan, which inspired quite a few students' comments on the intertextual title. The Disney song associated with (18) was also activated frequently. As several students put it, the song was ringing in their heads when they wrote about (18). The following three excerpts stand for such positive responses:

I think the main idea [of Iron Man] is really clear to anyone who has watched this movie. Since I like the series of Iron Man, I feel very excited when I see this title in the first time. This title makes me think about the scenes and characters in Iron Man. Therefore, I feel more interested in this title. It is really interesting that there is a connection between this title and my favorite movie.

'Three Little Pigs' is one of my favorite childhood stories. And 'Who's afraid of the big bad wolf' is its theme song. As soon as I saw the title [(18)], the melody of the song came up in my mind. The article deals with xenotransplantation, also related to pigs' organs. I think the headline was written in a perfectly felicitously way. It makes a very professional and difficult article so attractive. It has successfully aroused my desire to keep reading (Note 6).

I really like to watch the movie [Back to the Future]. Although I know the film [. . . ], I really know nothing about the singer Beck Hansen. Using film's name to grab readers' attention is a very impressive method. By changing only one letter, the writer makes me think that the article may have some relevant information of the movie. In fact, the content of the article has nothing to do with "Back to the future". It is about Beck's new album. [Whether] it is relevant to the film or not, it attracts me to go through everything successfully. 
It can be assumed that a particular group of intertext readers are more (or less) able to activate some types of intertexts than others because of related features of group membership. Take (14) as an example. As many as 10 students specifically indicated in their logs that the source text of (14) failed to attract them because of their non-Christian or non-Catholic backgrounds. In addition, 9 students attributed their lack of interest in (11) to their dislike of literature or Shakespeare's works. They were enrolled in a university where English education was characterized by emphasizing practical language skills. Very few literature courses were offered in their department, and most of the undergraduate students had never elected any literature courses. As noted earlier, the students were generally more interested in the intertexts that involve pop culture products. This is not surprising since pop culture generally plays a greater role in the lives of young people.

The reading-response logs (including the excerpts cited above) indicate that the students' familiarity with the source text is an important factor contributing to their comprehension and/or appreciation of a spiked intertext. The students having relevant intertextual background knowledge could notice the verbatim source text (as in (13)) or its adaptation (as in (17)) and comprehend the alluding text. By and large, they were positively disposed toward the intertext. But the background knowledge required to comprehend a PI is not readily available to every member of the cultural or linguistic community, especially when that PI is read cross-culturally by members of a foreign sociocultural group. Such cross-cultural intertexts, to put it in the words of Irwin (2002, p.523), have a "power to alienate as well as include". While trying to comprehend a foreign-derived intertext, especially if it contains unfamiliar proper names, the readers who are not conversant about the source text may find themselves in a bewildering state of ignorance and strangeness. The puzzling intertext fails to convey a coherent meaning to the alienated readers, let alone draw them into the body copy. This include-and-alienate effect can be observed in the reading-response logs. For instance, the title 'And a little child shall lead them' in (14) was looked upon by 15 students as one of the two most interesting titles, while another 25 students considered it to be one of the two most uninteresting.

A PI can be used not just to impart meaning but to achieve illocutionary and perlocutionary force as well. To produce or activate a PI (whether consciously or unconsciously) is to realize a specific pragmatic act, or an action that is more than just conveying or comprehending information. Quite a few students stated in their logs that an interesting PI got them to read the body copy, which is the perlocutionary potential of that PI. To realize its potential, the students had to construct the intertextual meaning by invoking their knowledge about the source text. The students who realized the perlocutionary potential were rewarded with a sense of pleasure or achievement (in the sense that they were properly informed of the relevant cultural materials and able to grasp the hidden meaning of the PI). On the other hand, the intertext repelled the unknowing students on the grounds that the PI failed to bring its performative potential into play; that is, it failed to create in the student's mind the link between the alluding and source texts and left the student bored with or confused about the text. The repelling of the unknowing students nullified some perlocutionary effect of the individual PI.

\section{Concluding Remarks}

A PI is a source of not only infotainment but also intellectual stimulation. It calls for reader activation and creativity. The meaning of a PI is not decoded or extracted, but activated and constructed. We have explored 172 instances of perlocutionary intertextuality in the titles of 615 spiked articles within the reader-oriented approach. It is found that, in conjunction with the common ground derived from the source text, a PI catches the reader's attention by foregrounding 1) a prominent or unusual aspect of the article and 2) a foreign element within the frame of the common ground. Thus the reader is induced to construct the meaning and significance of the PI through pragmatic inferencing based on internal paratextuality and external intertextualilty.

The post hoc questionnaire survey with 83 Taiwanese college students and their reading-response logs indicated that such intercultural PIs were moderately appealing after they were prompted with originally unknown intertextual sources. In addition, the individual PIs attracted knowing readers but repelled unknowing ones. The repellent cases nullified some perlocutionary effects of the PIs. Although a PI may draw on a source text not readily available to every member of even the host culture, it is still possible for a Western-derived PI to arouse the interest of foreign readers properly informed of the relevant sociocultural materials and to generate a pleasurable experience of dynamic meaning construction. Future research can be conducted 1) to confirm or modify the findings of the present study using data from more sources and 2) to explore the appeal of Eastern-derived intertexts to Western readers to show cultural symmetries or asymmetries.

\section{Acknowledgments}

The research carried out for the writing of this paper has been financed by Taiwan's National Science Council (NSC 100-2410-H-160-008-MY2). 


\section{References}

Albee, E., \& Kolin, P. C. (1988). Conversations with Edward Albee. Jackson, MS: University Press of Mississippi.

Alptekin, C. (2006). Cultural familiarity in inferential andliteral comprehension in L2 reading. System, 34, 494-508. http://dx.doi.org/10.1016/j.system.2006.05.003

Austin, J. L. (1962). How to do things with words. Oxford: Oxford UniversityPress.

Babuts, N. (2009). Memory, metaphors, and meaning: Reading literary texts. New Brunswick, NJ: Transaction Publishers.

Barrier, M. (2007). The animated man: A life of Walt Disney. Berkeley, CA: University of California Press.

Barthes, R. (1977). The death of the author. In S. Heath (Ed.), Image-music-text (S. Heath, Trans., pp. 142-148). New York: Hill and Wang.

Barthes, R. (1981). Theory of the text. In R. J. C.Young (Ed.), Untying the text: A post-structuralist reader (pp. 31-47). London: Routledge \& Kegan Paul.

Brunson, A. C. (2003). Psalm 118 in the Gospel of John: An intertextual study on the New Exodus pattern in the theology of John. Philadelphia: Coronet Books.

Capone, A. (2005). Pragmemes (a study with reference to English and Italian). Journal of Pragmatics, 37, 1355-1371. http://dx.doi.org/10.1016/j.pragma.2005.01.013

Clark, H. H. (2006). Context and common ground. In K. Allan (Ed.), Concise encyclopedia of semantics (pp. 155-158). Oxford, UK: Elsevier Ltd.

Cotrozzi, S. (2010). Expect the unexpected: Aspects of pragmatic foregrounding in Old Testament narratives. New York: T\&T Clark.

Delabastita, D. (1996). Introduction to wordplay and translation. The Translator, 2, 127-139. http://dx.doi.org/10.1080/13556509.1996.10798970

Fernando, C. (1996). Idioms and idiomaticity. Oxford: Oxford University Press.

Gale, M. R. (2000). Virgil on the nature of things: The Georgics, Lucretius and the didactic tradition. Cambridge: Cambridge University Press. http://dx.doi.org/10.1017/CBO9780511482182

Genette, G. (1997). Palimpsests: Literature in the second degree (C. Newman \& C. Doubinsky, Trans.). Lincoln, NB: University of Nebraska Press.

Hollander, J. (1981). The figure of echo: A mode of allusion in Milton and after. Berkeley, CA.: University of California Press.

Hopper, P. J., \& Thompson, S. A. (1980). Transitivity in grammar and discourse. Language, 56, 251-299. http://dx.doi.org/10.1353/lan.1980.0017

Hylen, S. (2005). Allusion and meaning in John 6. Berlin: Walter de Gruyter. http://dx.doi.org/10.1515/9783110920567

Irwin, W. (2001). What is an allusion? Journal of Aesthetics and Art Criticism, 59, 287-297. http://dx.doi.org/10.1111/1540-6245.00026

Irwin, W. (2002). The aesthetics of allusion. Journal of Value Inquiry, 36, 521-532. http://dx.doi.org/10.1023/A:1021961406123

Juvan, M. (2008). History and poetics of intertextuality (T. Pogača, Trans.). West Lafayette, IN: Purdue University Press.

Kecskes, I. (2000). A cognitive-pragmatic approach to situation-bound utterances. Journal of Pragmatics, 32, 605-625. http://dx.doi.org/10.1016/S0378-2166(99)00063-6

Kecskes, I. (2010). Situation-bound utterances as pragmatic acts. Journal of Pragmatics, 42, 2889-2897. http://dx.doi.org/10.1016/j.pragma.2010.06.008

Kecskes, I., \& Zhang, F. (2009). Activating, seeking, and creating common ground: A socio-cognitive approach. Pragmatics \& Cognition, 17, 331-355. http://dx.doi.org/10.1075/pc.17.2.06kec

Kristeva, J. (1967). Bakhtine, le mot, le dialogue et le roman. Critique, 23, 438-465.

Kristeva, J. (1969). Narration et transformation. Semeiotica, 1, 422-448. 
Kristeva, J. (1980). Desire in language: A semiotic approach to literature and art (T. Gora, A. Jardine, \& L. Roudiez, Trans.). New York: Columbia University Press.

Lakoff, G. (2004). Don't think of an elephant!Know your values and frame the debate. White RiverJunction, VT: Chelsea Green.

Lennon, P. (2004). Allusions in the press: An applied linguistic study. Berlin: Mouton de Gruyter. http://dx.doi.org/10.1515/9783110197334

Mathewson, D. (2003). Assessing Old Testament allusions in the book of Revelation. The Evangelical Quarterly, $75,311-325$.

Mey, J. L. (2001). Pragmatics: An introduction. Oxford: Blackwell Publishers.

Mey, J. L. (2010). Reference and the pragmeme. Journal of Pragmatics, 42, $2822-2888$. http://dx.doi.org/10.1016/j.pragma.2010.06.009

Miall, D. S., \& Kuiken, D. (1994). Foregrounding, defamiliarization, and affect: Response to literary stories. Poetics, 22, 389-407. http://dx.doi.org/10.1016/0304-422X(94)00011-5

Mukařovský, J. (1964). Standard language and poetic language. In P. L. Garvin (Ed.), A Prague School reader on esthetics, literary structure, and style (P. L.Garvin, Trans., pp. 18-30). Washington: Georgetown University Press.

O’Neill, B. (2011). Spiked: Still pointed after all these years. Spiked, March 8. Retrieved April 8, 2013, from http://www.spiked-online.com/index.php/site/article/10273/

Pasco, A. H. (1994). Allusion: A literary craft. Toronto: University of Toronto Press.

Paulien, J. (2001). Criteria and the assessment of allusions to the Old Testament in the book of Revelation. In S. Moyise (Ed.), Studies in the book of Revelation (pp.113-130). Edinburgh: T \& T Clark.

Perri, C. (1978). On alluding. Poetics, 7, 289-307. http://dx.doi.org/10.1016/0304-422X(78)90030-X

Polanyi, L., \& Hopper, P. J. (1981). A revision of the foreground-background distinction. Paper presented at the Annual Meeting of the Linguistic Society of America. New York. December 27-30.

Porter, S. E. (2008). Allusion and echoes. In S. E. Porter \& C. D. Stanley (Eds.), As it is written: Studying Paul's use of scripture (pp. 329-40). Atlanta, GA: Society of Biblical Literature.

Pucci, J. (1998). The full-knowing reader: Allusion and the power of the reader in the Western literary tradition. New Haven, CT: Yale University Press.

Ricks, C. (2002). Allusion to the poets. Oxford: Oxford University Press.

Ritter, H. (1986). Dictionary of concepts in history. Westport, CT: Greenwood Press.

Sadoski, M., Goetz, E. T., \& Fritz, J. B. (1993). A casual model of sentence recall: Effects of familiarity, concreteness, comprehensibility, and interestingness. Journal of Reading Behavior, 25, 5-16.

Schumacher, E. F. (1975). Small is beautiful: Economics as if people mattered. New York: Harper Perennial.

Shie, J. S. (2011a). Allusions in New York Times and Times Supplement news headlines. Discourse \& Communication, 5, 41-63. http://dcm.sagepub.com/content/5/1/41.full.pdf + html

Shie, J. S. (2011b). Metaphors and metonymies in New York Times and Times Supplement news headlines. Journal of Pragmatics, 43, 1318-1334.

http://www.sciencedirect.com/science/article/pii/S0378216610003607

Shie, J. S. (2012). Conceptual metaphor as a news story promoter: The cases of ENL and EIL headlines. Intercultural Pragmatics, 9, 1-21. http://dx.doi.org/10.1515/ip-2012-0001

Stalnaker, R. C. (2002). Common ground. Linguistics and Philosophy, 25, 701-721. http://dx.doi.org/10.1023/A:1020867916902

Straubhaar, J. D. (2007). World television: From global to local. Thousand Oaks, CA: Sage.

Teigen, K. H. (1985). The novel and the familiar: Sources of interest in verbal information. Current Psychological Research \& Reviews, 4, 24-238. http://dx.doi.org/10.1007/BF02686573

Thussu, D. K. (2007). News as entertainment: The rise of global infotainment. London: Sage.

Tseng, M. Y. (2010). The pragmatic act of fishing for personal details: From choice to performance. Journal of 
Pragmatics, 42, 1982-1996. http://dx.doi.org/10.1016/j.pragma.2009.12.004

Van Lancker Sidtis, D. (2004). When novel sentences spoken or heard for the first time in the history of the universe are not enough: Toward a dual-process model of language. International Journal of Language \& Communication Disorders, 39, 1-44. http://dx.doi.org/10.1080/13682820310001601080

Van Lancker Sidtis, D., \& Rallon, G. (2004). Tracking the incidence of formulaic expressions in everyday speech: Methods for classification and verification. Language \& Communication, 24, 207-240. http://dx.doi.org/10.1016/j.langcom.2004.02.003

Watts, S. (1997). The magic kingdom: Walt Disney and the American way of life. Boston: Houghton Mifflin.

\section{Notes}

Note 1. See http://www.spiked-online.com/newsite/about/336/(accessed 17 March 2014).

Note 2. The Times Supplement was published as a weekly pullout section within the print newspaper the United Daily News, one of the three biggest newspapers in Taiwan. The news articles in the Times Supplement were derived from The New York Times. Each Times Supplement article was edited lightly from a corresponding New York Times article, but most of the Times Supplement headlines were heavily rewritten, and hence different from their counterparts in The New York Times (see also Shie, 2011b).

Note 3. Still other titles may be viewed as both types (such as (10)), especially when the focus of the body copy presented in the title is interesting in itself.

Note 4. This except was translated from Mandarin Chinese by the present author.

Note 5. This except was translated from Mandarin Chinese by the present author.

Note 6. This except was translated from Mandarin Chinese by the present author.

\section{Copyrights}

Copyright for this article is retained by the author(s), with first publication rights granted to the journal.

This is an open-access article distributed under the terms and conditions of the Creative Commons Attribution license (http://creativecommons.org/licenses/by/3.0/). 